OPEN ACCESS

Edited by:

Nuno Queiroz,

Centro de Investigacao em Biodiversidade e Recursos Geneticos (CIBIO-InBIO), Portugal

Reviewed by: Yuri Niella

Macquarie University, Australia Colin Simpfendorfer,

James Cook University, Australia

*Correspondence:

Chantel Elston

chantel.elston@gmail.com

Specialty section

This article was submitted to

Marine Megafauna,

a section of the journal

Frontiers in Marine Science

Received: 06 August 2021

Accepted: 29 November 2021

Published: 13 January 2022

Citation:

Elston C, Cowley $P D$, von Brandis RG and Lea J (2022) Stingray Habitat Use

Is Dynamically Influenced by

Temperature and Tides.

Front. Mar. Sci. 8:754404.

doi: 10.3389/fmars.2021.754404

\section{Stingray Habitat Use Is Dynamically Influenced by Temperature and Tides}

\author{
Chantel Elston ${ }^{1 *}$, Paul D. Cowley ${ }^{2}$, Rainer G. von Brandis ${ }^{3}$ and James Lea ${ }^{3,4}$ \\ ${ }^{1}$ Department of Ichthyology and Fisheries Science, Rhodes University, Grahamstown, South Africa, ${ }^{2}$ South African Institute \\ for Aquatic Biodiversity, Grahamstown, South Africa, ${ }^{3}$ Save Our Seas Foundation - D'Arros Research Centre, Geneva, \\ Switzerland, ${ }^{4}$ Department of Zoology, University of Cambridge, Cambridge, United Kingdom
}

Abiotic factors often have a large influence on the habitat use of animals in shallow marine environments. Specifically, tides may alter the physical and biological characteristics of an ecosystem while changes in temperature can cause ectothermic species to behaviorally thermoregulate. Understanding the contextual and relative influences of these abiotic factors is important in prioritizing management plans, particularly for vulnerable faunal groups like stingrays. Passive acoustic telemetry was used to track the movements of 60 stingrays at a remote and environmentally heterogeneous atoll in Seychelles. This was to determine if habitat use varied over daily, diel and tidal cycles and to investigate the environmental drivers behind these potential temporal patterns. Individuals were detected in the atoll year-round, but the extent of their movement and use of multiple habitats increased in the warmer NW-monsoon season. Habitat use varied over the diel cycle, but was inconsistent between individuals. Temperature was also found to influence stingray movements, with individuals preferring the deeper and more thermally stable lagoon habitat when extreme (hot or cold) temperature events were observed on the flats. Habitat use also varied over the tidal cycle with stingrays spending a higher proportion of time in the lagoon during the lowest tides, when movement on the flats were constrained due to shallow waters. The interplay of tides and temperature, and how these varied across diel and daily scales, dynamically influenced stingray habitat use consistently between three species in an offshore atoll.

Keywords: acoustic telemetry, spatial ecology, GLMM, St Joseph Atoll, Dasyatidae

\section{INTRODUCTION}

Understanding how and why animals move is a key topic in animal spatial ecology (Morris, 2003). This knowledge assists in predicting where animals will occur and how they will move, and further informs how animals will respond to anthropogenic influences such as climate change or habitat degradation (Sakabe and Lyle, 2010; Speed et al., 2012; Vaudo and Heithaus, 2013; Schlaff et al., 2014). However, several literature reviews have shown that most tracking studies report on the when and where animals occur and only a few have identified the drivers (Sims, 2010; Hammerschlag et al., 2011; Flowers et al., 2016). Furthermore, habitat selection will be influenced by the link between an animal's physiology and its external environment. The physiological state of an animal will be optimized under a subset of environmental conditions and animals may avoid habitats where such environmental conditions are sub-optimal (Brown et al., 2004). These environmental thresholds may be species- or population- specific, allowing each to exploit different ecosystems (Fangue and Bennett, 2003; Dabruzzi et al., 2013). 
Shallow marine environments (e.g., intertidal zones) are dynamic in nature and the selection of appropriate habitats within these environments will depend on a variety of physical factors (such as temperature, tidal flow, salinity) and biological processes (such as predation risk and prey availability) (Sims, 2003; Carlisle and Starr, 2010; Speed et al., 2010). The dynamism of these factors is often manifested over a variety of temporal scales and animal movement patterns may change over largescale seasonal cycles, for example annual migrations (Bauer and Klaassen, 2013; Chapman et al., 2015), to smaller-scale diel and tidal cycles, for example a change in habitat use during nocturnal/crepuscular periods (Hammerschlag et al., 2017) or during high tides (Lea et al., 2020).

Tides specifically, and the associated changes in water levels, will potentially have one of the strongest impacts on animal movement in shallow environments as it influences all other physical aspects of the water column such as temperature and oxygen concentration (as seen in Carlisle and Starr, 2010; Brinton and Curran, 2017; Smith and Curran, 2017). Tides also influence biotic factors including predation risk, as predators may become physically unable to access very shallow waters during low tide periods, and by changes in prey availability within inter-tidal flats. Indeed, tides are a significant driver of the movement of a number of marine taxa including seabirds, where individuals alter habitat use or foraging activities with the tide (Rogers et al., 2006; Rey et al., 2010), teleosts which have been found to move with the ebb and flow of the tide (Næsje et al., 2012), and elasmobranchs who move with the tide to forage over larger areas or to find refuge areas at high tide (Carlisle and Starr, 2010; Filmalter et al., 2013; Davy et al., 2015; Lea et al., 2020).

When considering the biology of elasmobranchs, their ectothermic nature means that temperature, in particular, can have a significant effect on physiological and biological aspects such as growth and metabolic rates, embryonic development, parturition, and the rate of digestion (Fangue and Bennett, 2003; Hight and Lowe, 2007; DiGirolamo et al., 2012; Dale et al., 2013). Consequently, temperature influences elasmobranch movement and certain species exhibit behavioral thermoregulation (whereby individuals will select habitats in a thermally heterogeneous environment to maintain body temperatures within an optimal range) in both field and laboratory environments. Thermoregulatory behaviors often manifest over diel and seasonal scales, given that temperature fluctuates across these temporal scales (Matern et al., 2000; Hopkins and Cech, 2003; Sims et al., 2006; Vaudo and Lowe, 2006; DiGirolamo et al., 2012; Speed et al., 2012).

As there are multiple drivers behind habitat selection, the relative importance of these will be context-dependent and tradeoffs are likely to be necessary (Schlaff et al., 2014). For example, batoids have been shown to select shallow nearshore habitats at low tide, which may serve as a refuge from predation or competitive effects, but these habitats are likely metabolically expensive due to high temperatures and lower levels of dissolved oxygen (Vaudo and Heithaus, 2013; Dabruzzi and Bennett, 2014). Understanding which aspects of the environment drive habitat choice is necessary to elucidate the habitat attributes that maintain biodiversity, which is useful for prioritizing management or conservation initiatives for vulnerable faunal groups such as stingrays, where approximately $56 \%$ of species considered as threatened (Lea et al., 2016; Dulvy et al., 2021).

Consequently, this study aimed to investigate the influence of selected environmental factors on the daily presence to, and habitat use within, a shallow remote atoll by 3 sympatric stingray species. Firstly, it was investigated if presence to this offshore atoll by stingrays was influenced by seasonal variables such as temperature, precipitation, and wind speeds. Secondly, habitat use within the atoll was investigated to determine if presence in the deeper lagoon or shallow reef flat habitats were influenced by heterogenous environmental variables such as water temperature, tidal height, precipitation and diel stage. The extent to which these environmental variables influence habitat selection may inform why stingrays occur where they do.

\section{MATERIALS AND METHODS}

These methods were approved by the South African Institute for Aquatic Biodiversity Animal Ethics Committee (reference number 2014/12) and by the Ministry of Environment, Energy, and Climate Change, Seychelles. All analyses were conducted in R (version 3.6.3) (R Core Team, 2020).

\subsection{Study Site}

This study was conducted at the remote St. Joseph Atoll, Seychelles, in the western Indian Ocean $\left(5.43^{\circ} \mathrm{S}, 53.35^{\circ} \mathrm{E}\right)$. The atoll (area of $\sim 22.5 \mathrm{~km}^{2}$ ) is comprised of two major habitat types: a shallow uninterrupted reef flat that lacks a tidal channel (17.7 $\mathrm{km}^{2}$ ) and a deeper (3-9 $\mathrm{m}$ depth) enclosed lagoon (4.8 $\mathrm{km}^{2}$ ) (Stoddart et al., 1979). The flats are dominated by large areas of sand flats scattered with seagrass beds (largely Thalassia hemprichii and Thalassendron ciliatum) (Figure 1). The lagoon is mostly comprised of a sandy benthos with numerous large poriitid and flaviid coral outcrops that rise to the surface. The atoll supports an abundance of marine megafauna including sharks, rays and turtles (Filmalter et al., 2013; Lea et al., 2016), and has been identified as a nursery area for three stingray species (Pastinachus sephen, Urogymnus granulatus, and Urogymnus asperrimus) (Elston et al., 2021).

The atoll occurs in a tropical region that experiences two seasons: the south-east (SE) monsoon from April-November and the north-west (NW) monsoon from December to March. Although seasonal variability is low compared to temperate regions, it does represent some level of heterogeneity. Specifically, the SE monsoon experiences strong persistent south-easterly winds with lower precipitation and temperatures. The NW monsoon is characterized by light north-westerly winds with higher temperatures and precipitation.

The atoll is governed by a semidiurnal tidal phase and while the tidal range is narrow $(\sim 2 \mathrm{~m})$, it is large enough to create a highly heterogeneous environment on the flats. These flats are largely exposed or covered with very shallow water (10$30 \mathrm{~cm}$ depth) at the lowest tides but can be covered with up to $2 \mathrm{~m}$ of water at the highest tides. The flats are also heterogeneous in terms of water temperature, which varies significantly across the diel cycle, with peaks during the late 
afternoon and the lowest values at dawn. Conversely, the lagoon represents a more environmentally stable habitat type and temperatures are relatively consistent over the diel cycle (Supplementary Figure 1).

\subsection{Acoustic Telemetry}

Between March 2014 and May 2015, a total of 60 stingrays, comprising 20 individuals from three different species (P. sephen, $U$. granulatus, and $U$. asperrimus) were surgically implanted with acoustic transmitters. Details and of capture and surgery procedures can be found in Elston et al. 2021). Individuals consisted of both males and females and spanned the range of sizes present in the atoll (Table 1). Transmitters were a mixture of V9, V13, and V16 (Innovasea, Amirix Inc., Bedford, NS, Canada) transmitters with various nominal delays.

Stingrays were passively tracked using an array of 40 acoustic receivers located in St. Joseph Atoll (Figure 1). These receivers were spread across the reef flats and lagoon habitats, as well as on the external fringing reef of the atoll. As detections on receivers along this fringe reef were negligible (Elston et al., 2021), analyses looking at habitat use only considered detections in the reef flat and lagoon habitat. Receiver installation was completed in November 2014 and only detection data recorded subsequent to this date were included in the analyses. A month long range test was conducted on the flats, given environmental factors may effect detection probability the most in this shallow habitat, and the probability of detection was found to significantly vary with wind speed but not with tidal cycles or temperature (Elston et al., 2019).

\subsection{Environmental Data}

A variety of detailed local environmental variables were recorded for the duration of this study. A weather station (Davis Vantage Pro2) was situated on the neighboring D'Arros Island

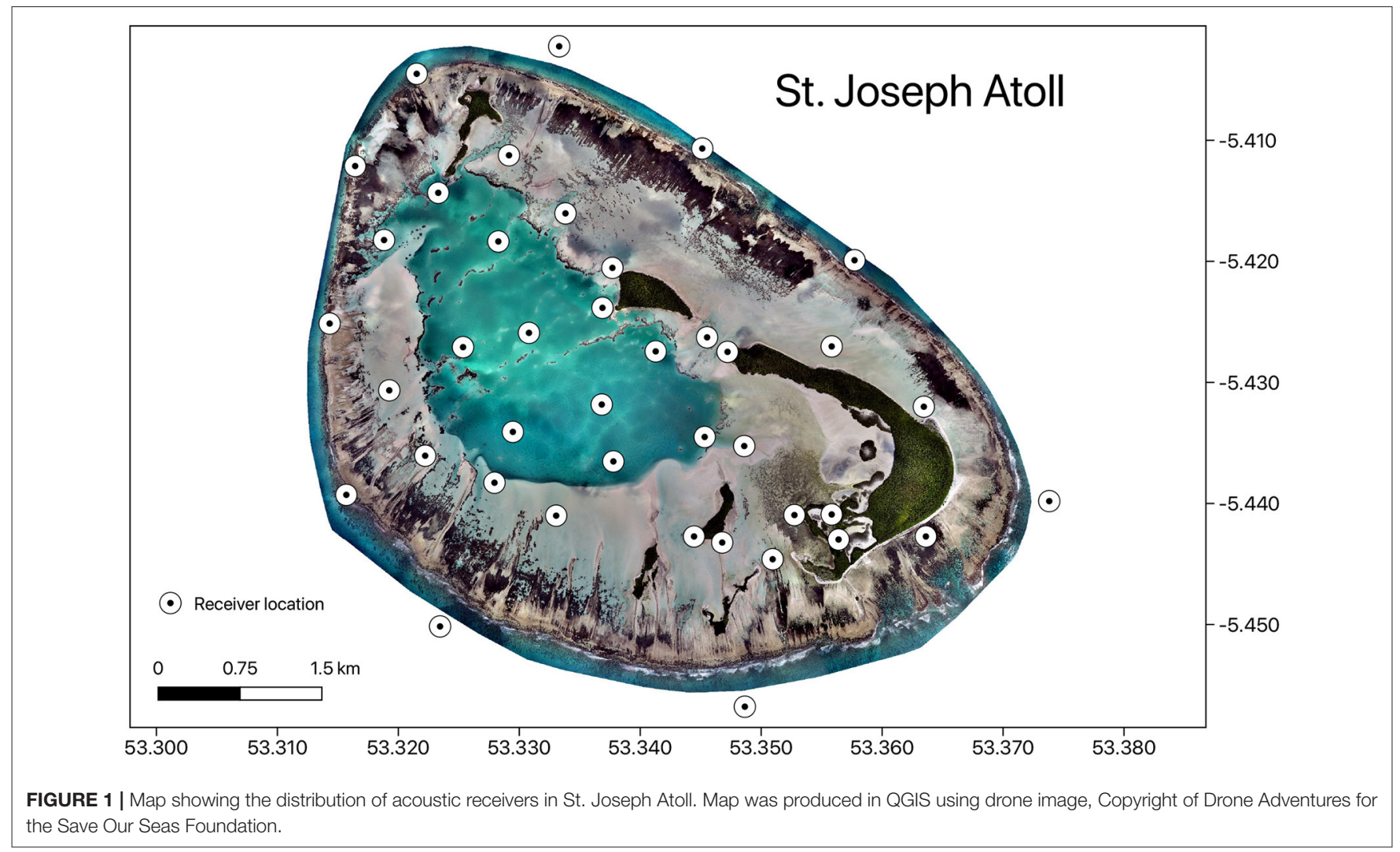

TABLE 1 | A summary of the acoustically tracked stingrays used in analyses.

\begin{tabular}{|c|c|c|c|c|c|c|}
\hline Species & \# Tracked & \# Males & \# Females & Mean DW (cm) & DW range $(\mathrm{cm})$ & Mean time at liberty (days) \\
\hline Pastinachus ater & 20 & 10 & 10 & 71 & 49-104 & 389 \\
\hline Urogymnus granulatus & 20 & 15 & 5 & 62 & $30-81$ & 297 \\
\hline Urogymnus asperrimus & 17 & 11 & 6 & 62 & $53-73$ & 518 \\
\hline
\end{tabular}

DW, disc-width. 
(approximately $1 \mathrm{~km}$ west of St. Joseph Atoll) to record weather parameters such as air temperature, wind speed and direction, rainfall, barometric pressure at half-hourly intervals. Each acoustic receiver was coupled with a sea temperature logger (HOBO Water Temperature Pro v2 Data Logger, Onset, Bourne, USA) which recorded the water temperature at 10 min intervals. A pressure logger (HOBO Water Level Data Logger, Onset, Bourne, USA) was deployed in the lagoon of the atoll to record water pressure for a 6-month period. The tidal height in meters was then calculated using the known depth of the logger. Tidal cycles were modeled using the Oregon State University Tidal Model Driver (Egbert and Erofeeva, 2002) with the harmonics for St. Joseph Atoll. The model predicted accurate tidal heights for the atoll in $10 \mathrm{~min}$ intervals for the entire study period (predictions differed only by $1.96 \%$ compared to the logger recordings) (Lea et al., 2020).

\subsection{Environmental Effects on Daily Presence to Atoll}

Network analysis was used to visualize movement patterns and compare the extent of daily space use across the entire study period. In this approach, receivers are treated as nodes and pairs of subsequent detections at different receivers are treated as edges (Jacoby et al., 2012). Two network metrics were then calculated to quantify the extent of space used: node density, defined as the proportion of available nodes in the network that were used, and edge density, defined as the proportion of available edges in the network used. Networks were constructed and metrics calculated for each individual for both seasons using the R package iGraph (Csardi and Nepusz, 2006). Only edges that occurred within $24 \mathrm{~h}$ of each other were considered. Generalized linear mixed models (GLMMs) were used to determine if edge and node densities significantly differed between each season. Covariates in the models included season, time (a numeric vector indicating the number of seasons passed since time of tagging), and size and sex of the individual, given that these factors may also influence space use. A binomial distribution with a logit link was chosen as both edge and node densities reflect proportions of the network utilized. Models were run separately for each species.

To identify which environmental factors may have influenced daily stingray presence in the atoll, GLMMs were used to determine if daily presence to the atoll (coded as 0 for absent and 1 for present for each individual) was effected by mean daily air temperature, precipitation, and wind speed. Individual and month were included as random effects in the model to account for non-independence. Data from both $P$. ater and $U$. granulatus that spanned a 1-year period (1 June 2015-31 May 2016) was used. These analyses (network and modeling approaches) excluded data for $U$. asperrimus as daily movement patterns for this species have already been investigated (Elston et al., 2017).

For all models, an information theoretic procedure was followed to select the best performing model. In each instance, a global model was developed that included all covariates using the "glmer" function from the lme4 library (Bates, 2010). The "dredge" function in the MuMIn package was then used to create subsets of models with all possible combinations of the chosen factors. Akaike's information criterion corrected for small-sample bias (AICc) were then used to rank the models. If top performing models had a $\triangle \mathrm{AICc}<2$, model averaging was performed to produce average parameter estimates based on the top models. Model assumptions were checked by plotting residuals and models were checked for over-dispersal. If models were overdispersed, quasi-Akaike's information criterion corrected for small samples (QAICc) was used to rank the models.

\subsection{Environmental Effects on Habitat Use}

The proportions of hourly detections (over the $24 \mathrm{~h}$ diel cycle) were used to investigate whether there were diel peaks in detections for each habitat type for all three stingray species. Detections were filtered so that only the first detection for every hour for each individual was kept to account for the influence of large numbers of detections when individuals were detected at the same receiver for extended periods and to reduce possible effects of receiver detection efficiency in analyses. Each acoustic detection was assigned to an hourly bin (0-23), and the total number of detections for each hourly bin was summed across individuals. Chi-squared tests were used to determine whether hourly detections differed from an even distribution for each individual. A permutational multivariate analysis of variance (PERMANOVA), which considers both categorical and continuous independent variables (Anderson, 2001), was used to determine whether stingray species, sexes or sizes utilized the receiver array differently over the diel cycle. A Euclidean dissimilarity matrix was developed, based on the proportion of detections in each hourly bin for each individual. The adonis function in the $\mathrm{R}$ vegan package was used to perform the PERMANOVA (Anderson, 2001). Analyses were conducted separately for the reef flats and lagoon habitats.

To investigate the role of tides on habitat use by stingrays, acoustic detections recorded by individuals were binned into $10 \mathrm{~cm}$ tidal height bins based on the tidal height that matched each detection. Additionally, the tidal height values calculated by the tidal model over the study period were also binned into 10 $\mathrm{cm}$ categories. A chi-squared test was then used to determine if the distribution of acoustic detections was significantly different from the distribution of the modeled tidal heights across the study period. These analyses were conducted separately for the reef flats and lagoon habitats.

To identify which environmental factors may have influenced stingray habitat use on a fine temporal scale, GLMMs were used to determine if habitat use (coded as 0 for lagoon or 1 for reef flats presence) was influenced by water temperature on the flats, tidal height, precipitation (which likely effects salinity in the shallow waters) and diel stage. The latter was coded as dawn (05:00-07:00), day (08:00-16:00), dusk (17:00-19:00), and night (20:00-04:00). All covariates were tested for collinearity (those with VIF scores $<3$ were considered to not be collinear and were included in models). Every detection was coded as either a reef flat or lagoon detection and was matched to the temporally closest environmental variables. Because of this GLMM set-up, if the probability of being detected on the flats increased, it automatically followed that the probability of detection in the lagoon decreased (and vice-versa). Individual and month were included as random effects in the model to account for nonindependence. In addition, models were run separately for each species and for each season. Four months of telemetry data in 
each season were analyzed for both $P$. ater and $U$. asperrimus (SE-monsoon: 1 June 2015-31 September 2015, NW-monsoon: 1 December 2015-31 March 2016). Telemetry data collected in the prior year was analyzed for $U$. granulatus and only spanned one season (1 June 2014-30 September 2014) as most individuals were no longer detected in the NW-monsoon season subsequent to tagging. The same information theoretic approach to model selection as described above was followed.

\section{RESULTS}

Stingrays were monitored for a mean of $345 \pm 307$ (SD) days from April 2014-October 2017. Most individuals (87\%) were considered juveniles at the time of tagging. Residency to the atoll was found to be variable between individuals, but overall quite high, and periods of no detections (which could be related to individuals being present in the atoll but not detected, or having left the atoll) were mostly on the scale of days, but could range up to a few months of no detections (Elston et al., 2019).

\subsection{Environmental Effects on Daily Presence to Atoll}

Stingrays were detected in St. Joseph Atoll year-round but there were significant differences in the extent of space used in the atoll between the NW- and SE-monsoon seasons. The best fit GLMMs for network metrics included season as a significant predictor of both edge and node densities for $P$. ater, with both metrics being significantly higher in the warmer NW-monsoon season. Best fit models also included the number of seasons passed and disc-width as significant predictors of network metrics, and these were both positively correlated network metrics (Table 2 and Supplementary Table 1). Models would not converge for $U$. granulatus due to insufficient data, but trends were similar.

Network maps with edges summed across individuals provided a visualization of this increased space use in the atoll during the NW-monsoon season (Figure 2). For both species,

TABLE 2 | Outputs of the Generalized Linear Mixed Models testing whether season, time, and individual disc-width (DW) and sex influenced metrics from network analysis (edge and node densities of networks) performed on acoustic detections for $P$. ater.

\begin{tabular}{lcccc}
\hline \multicolumn{5}{c}{ Edge density } \\
\hline Covariate & Co-efficient estimate & Std. error & z-value & p-value \\
(Intercept) & -7.96 & 0.61 & -13.01 & $<0.01$ \\
Season (SE) & -0.31 & 0.07 & -4.13 & $<0.01$ \\
DW & 0.04 & 0.01 & 5.26 & $<0.01$ \\
Sex (m) & 0.03 & 0.22 & 0.13 & 0.9 \\
Time & 0.14 & 0.04 & 3.37 & $<0.01$ \\
\hline & & Node density & & \\
\hline Covariate & Co-efficient estimate & Std. error & $\mathbf{z}$-value & p-value \\
(Intercept) & -3.90 & 0.38 & -10.41 & $<0.01$ \\
Season (SE) & -0.38 & 0.15 & -2.55 & 0.01 \\
DW & 0.03 & 0.01 & 5.66 & $<0.01$ \\
Sex (m) & 0.03 & 0.01 & 6.36 & 0.84 \\
Time & 0.27 & 0.10 & 2.82 & $<0.01$
\end{tabular}

there was an increased use of the lagoon habitat, and to a lesser extent the fringe reef habitat, during this warmer season. Conversely, these habitats were not used in the cooler SEmonsoon season.

The probability of $P$. ater being detected in the atoll on a daily basis was significantly influenced by wind speed and air temperature, while rainfall had a minor and insignificant effect (Supplementary Table 2). The probability of daily presence was negatively correlated with wind speed and positively correlated with temperature (Table 3). There was limited evidence of environmental factors influencing $U$. granulatus daily presence to the atoll as the null model performed the best (Supplementary Table 2) and factors were insignificant (Table 3).

\subsection{Environmental Effects on Habitat Use}

The proportion of hourly detections for all individuals (barring one) differed significantly from an even distribution in the flats habitat (chi-squared tests, $p<0.01$ ). However, there was individual variation within species in peaks of hourly detections: 14 individuals had peaks in their detection frequencies around dawn and/or dusk, 12 had peaks during the day (mostly between 12:00 and 15:00), and 5 had peaks during the night (Figure 3). Only $U$. granulatus individuals displayed consistent trends with all individuals having peaks in detections at dawn/dusk. For the lagoon habitat, only half of the individuals displayed significant hourly peaks in detections, and again, variability was present at the individual level, rather than species level (some were absent from this habitat or had a very low number of detections) (chisquared tests, $p<0.01$ ). Seven individuals had peaks in detection frequencies during the day and five had peaks during the night. Three had peaks during both the day and night (Figure 3). This high individual variability did not seem to be related to biological traits as the different species, sexes and sizes did not differ significantly in their hourly proportions of detections in the flats or lagoon habitat (however, a significant difference was found between species in the lagoon habitat) (Table 4).

Tidal height had a constant significant effect on habitat utilization for all individuals, as the distribution of detections in each tidal height bin was significantly different to the distribution of tidal height occurrences (for each habitat and for each species) (chi-squared tests, $p<0.01$ ). Detections in the lagoon habitat peaked at low tides $(<0.5 \mathrm{~m})$ while detections on the sand flats were slightly higher at the highest tides $(>1.7 \mathrm{~m})$ (Figure 4).

The best-fit GLMMs further confirmed these results and highlighted that the diel stage (i.e., dawn/day/dusk/night) and tidal height had a significant effect on the habitat use of all three stingray species in both seasons (Supplementary Table 3). The probability of being detected on the flats was highest at night for both $P$. ater and $U$. asperrimus, while it was highest at dusk for $U$. granulatus. The probability of detections on the flats was positively correlated to tidal height in both seasons for all species (Table 5). Additionally, water temperature on the flats was a further significant effect on habitat use, except for $U$. asperrimus and $U$. granulatus in the SE-monsoon season (Supplementary Table 3), and it was found to affect habitat use differently in each season. For $P$. ater and U. asperrimus, 
there was a higher probability of detections on the sand flats with increasing temperatures in the SE-monsoon seasons, while there was a lower probability of detections on the flats with increasing temperatures in the NW-monsoon season (Table 5). While temperatures on the flats could exceed that of $45^{\circ} \mathrm{C}$, individuals were not detected on the flats at temperatures above $36^{\circ} \mathrm{C}$ (Figure 5).

\section{DISCUSSION}

This study revealed the nuanced ways in which the environment can effect stingray movement and habitat use patterns over a variety of temporal scales. Specifically, the interplay between tide and temperature, and how these changed across seasonal and diel scales, significantly effected the way that stingrays used the dominant habitats associated with the St. Joseph Atoll. Previous work found that juvenile stingrays in this atoll preferentially utilized the shallow sand flat habitat, but did at times occur in the deeper lagoon (Elston et al., 2019, 2020). The present study suggests that movements between these

TABLE 3 | Outputs of the Generalized Linear Mixed Models testing whether mean daily air temperatures, wind speeds or precipitation influenced the probability of $P$. ater and $U$. granulatus being detected in St. Joseph Atoll on a daily basis.

\begin{tabular}{lcccc}
\hline \multicolumn{5}{c}{$\boldsymbol{P}$ ater } \\
\hline Covariate & Co-efficient estimate & Std. error & z-value & p-value \\
(Intercept) & 1.08 & 1.35 & 0.80 & 0.42 \\
Temp & 0.07 & 0.05 & 1.40 & 0.16 \\
Wind & -0.08 & 0.01 & 5.28 & $<0.01$ \\
Rain & -0.15 & 0.16 & 0.93 & 0.35 \\
\hline \multicolumn{5}{c}{ U. granulatus } \\
\hline Covariate & Co-efficient estimate & Std. error \\
(Intercept) & 1.89 & 1.39 & z-value & p-value \\
Temp & 0.03 & 0.09 & 0.3 & 0.18 \\
Wind & -0.03 & 0.03 & 1.22 & 0.76 \\
Rain & -0.22 & 0.33 & 0.67 & 0.5
\end{tabular}

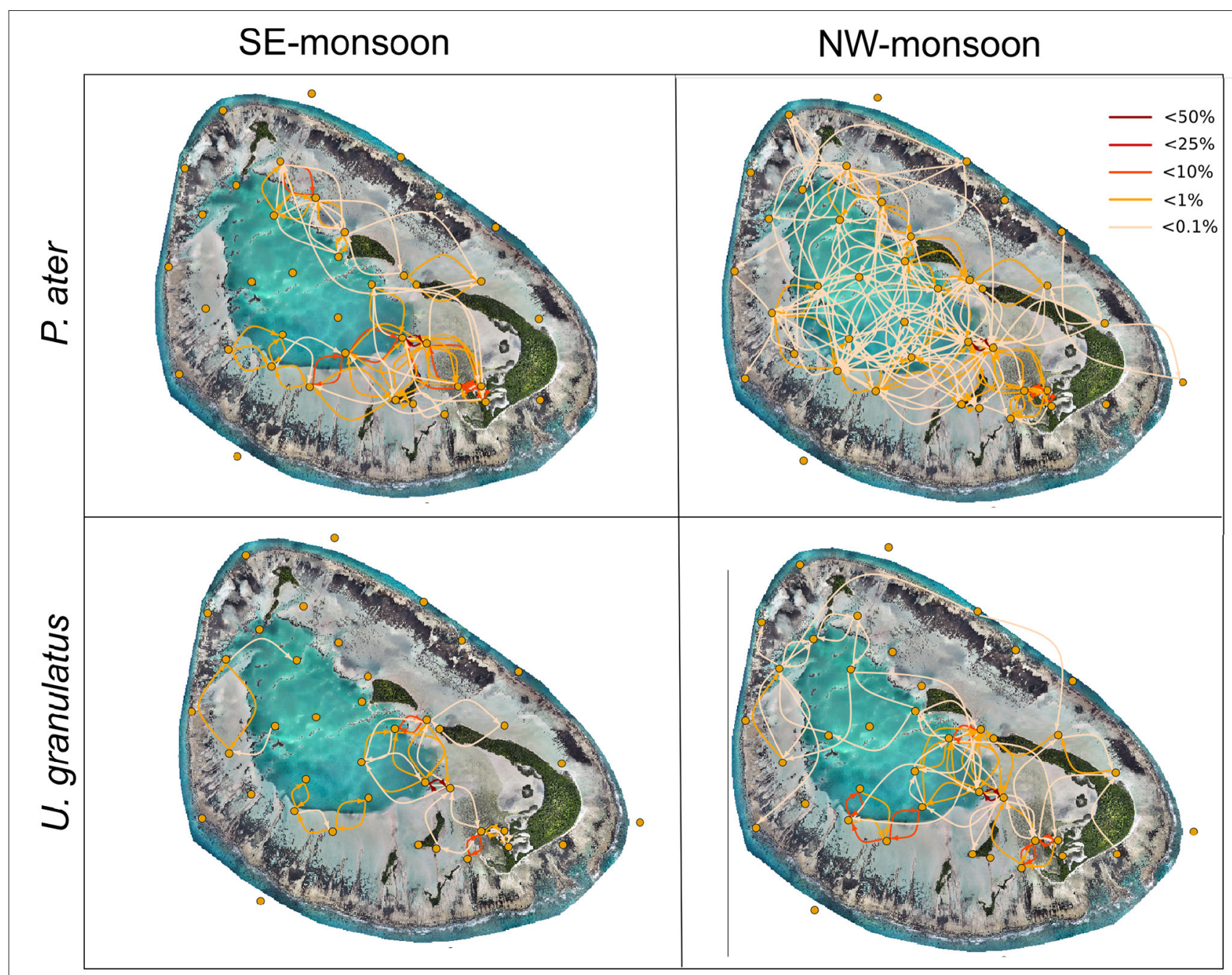

FIGURE 2 | Seasonal networks constructed for acoustically tagged stingrays (networks summed for all tagged individuals). Yellow dots represent nodes (acoustic receivers). Lines between nodes represent edges (movements between receivers). The color of the edge represents the proportions of movements between receivers. Map was produced using drone image, Copyright of Drone Adventures for the Save Our Seas Foundation. 


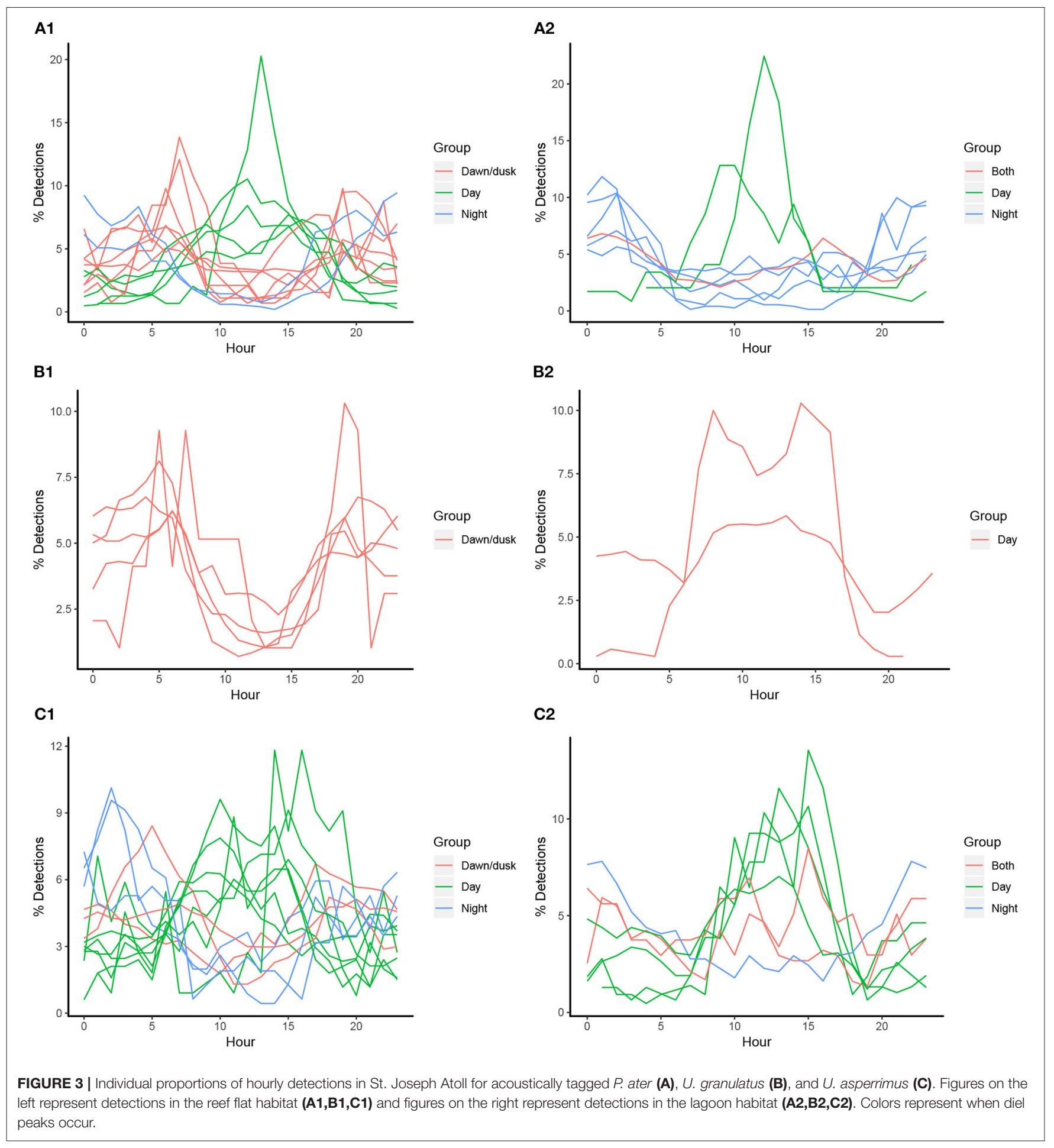

two habitat types were influenced by temperature and tidal height.

The daily presence of stingrays to the atoll was, in part, correlated with changes in temperature and wind speed. Stingrays were more likely to be detected in the atoll when daily temperatures were higher and when wind speeds were lower, conditions which correspond to the $\mathrm{NW}$-monsoon season. Furthermore, individuals were found to increase the spatial extent of their movements in the atoll in the warmer $\mathrm{NW}$ monsoon season, similarly to what was previously found for 
TABLE 4 | Results of the PERMANOVA performed on the proportion of detections in each hour (over the 24 diel cycle) for each tagged stingray.

\begin{tabular}{|c|c|c|c|c|c|c|c|c|}
\hline & \multicolumn{4}{|c|}{ Flats } & \multicolumn{4}{|c|}{ Lagoon } \\
\hline Species & 2 & 1.07 & 0.06 & 0.40 & 2 & 1.89 & 0.11 & 0.04 \\
\hline Size & 1 & 1.31 & 0.03 & 0.23 & 1 & 2.34 & 0.07 & 0.05 \\
\hline Sex & 1 & 1.22 & 0.03 & 0.30 & 1 & 1.11 & 0.03 & 0.31 \\
\hline Residuals & 33 & 0.88 & & & 28 & 0.79 & & \\
\hline
\end{tabular}

Independent variables included species, size (DW cm), and sex.

U. asperrimus juveniles (Elston et al., 2017). This trend was partially driven by the increased utilization of the lagoon and fringe reef habitats in the NW-monsoon season; habitats that are deeper and cooler compared to the shallow sand flats. This suggests that one of the reasons behind this movement pattern was temperature and that stingrays were potentially behaviorally thermoregulating, seeking out cooler habitats during the warmest time of the year. A similar finding was reported for juvenile stingrays that roamed less widely in a coastal bay in Australia during cooler months (Cerutti-Pereyra et al., 2014) and many other studies have identified batoids moving to actively exploit optimal thermal conditions (Matern et al., 2000; Fangue and Bennett, 2003; Vaudo and Lowe, 2006; Dabruzzi et al., 2013).

Temperature was also found to influence habitat use over fine temporal scales, a response that was found to differ between seasons. Specifically, stingrays appeared to avoid temperature extremes, seeking out the thermal stability of the lagoon when temperatures on the flats became too high or low. The tropical location of the atoll means temperatures do not fluctuate between seasons as much as they do in temperate regions. However, the physical properties of the different habitats means that temperatures on the shallow flats fluctuate quite significantly (approximately $15^{\circ} \mathrm{C}$ ). For both $P$. ater and $U$. asperrimus, when temperatures on the flats were lower during the cooler SE-monsoon season, individuals occurred more frequently at these times in the contextually warmer lagoon. Similarly, when temperatures on the flats were higher during the warmer NWmonsoon season, juveniles occurred more frequently at these times in the contextually cooler lagoon. Furthermore, warm temperatures appeared to influence habitat use more than cold temperatures, as models predicted temperature to have a larger influence on habitat use in the warmer NW-monsoon season compared to the cooler SE-monsoon season. These results suggest that the use of the lagoon habitat was, at least in part, influenced by temperature. This apparent behavior to remain within a thermal niche and to avoid temperature extremes may ensure that physiological processes are continually optimized. High temperatures may increase metabolic rates to sub-optimal levels, while low temperatures may slow down growth rates too much (Dale et al., 2013). The preference to remain in a narrow thermal niche has been witnessed in a laboratory setting where tropical juvenile ribbontail stingrays Taeniura lymna were found to have small thermal niches and individuals actively moved in tanks to remain in this narrow thermal niche (Dabruzzi et al., 2013).
Conversely, when considering U. granulatus, temperature was not found to significantly influence habitat use, raising questions as to whether this species may be more thermally tolerant in comparison to the other two. Laboratory studies show that different species can have different thermal tolerances (Fangue and Bennett, 2003; Dabruzzi et al., 2013) however, speciesspecific responses to temperature changes in the wild remain an enigma as the majority of studies that investigate the influence of temperature on batoid movement only consider one species (Cartamil et al., 2003; Vaudo and Lowe, 2006; Jirik and Lowe, 2012). It is important to note that these results must be treated with caution as there was only limited data for one season (SEmonsoon) for this species, and that more multi-specific research is needed to determine how different species respond to the same thermal environment.

Stingray habitat use was not only influenced by temperature, but also by the tides. Detections on the flats occurred throughout the tidal cycle (although were somewhat more frequent at high tides), while detections in the lagoon occurred at a significantly higher proportion at low tides. Given that stingrays are dorsoventrally flattened, they can occur in very shallow waters and indeed, the majority of detections for these stingrays occurred on the shallow flats (Elston et al., 2021). The high use of the flats by stingrays was likely a function of predator avoidance. The lagoon presents a significant predation risk as sharks display fidelity to this habitat (Filmalter et al., 2013; Lea, 2017) and juvenile stingrays were occasionally observed with shark bites on their pectoral fins (personal observations). Conversely, while sharks have also been shown to increase their use of the flats at high tide in the atoll (Lea, 2017; Lea et al., 2020), this habitat likely still provides refuge opportunities for dorsoventrally-flattened stingrays that can make use of shallow island fringes or sand banks that are more inaccessible to sharks. Further support for this predator avoidance hypothesis comes from the evidence that juveniles preferentially occurred on the flats, whilst adults (which are at lesser risk to predation) preferentially occurred in the lagoon (Elston et al., 2021). This behavior has been observed in an inter-tidal bay, where U. granulatus juveniles moved in a directed way during flooding and ebbing tides, remaining in shallow water, which was hypothesized to be a predator avoidance strategy (Davy et al., 2015). However, despite the reduction of predation risk on the flats, some regions of this habitat may become exposed at low tide, thus presenting a high risk of stranding and restricting movement in this habitat. This likely necessitates that stingrays seek out deeper waters at low tide, and 
A

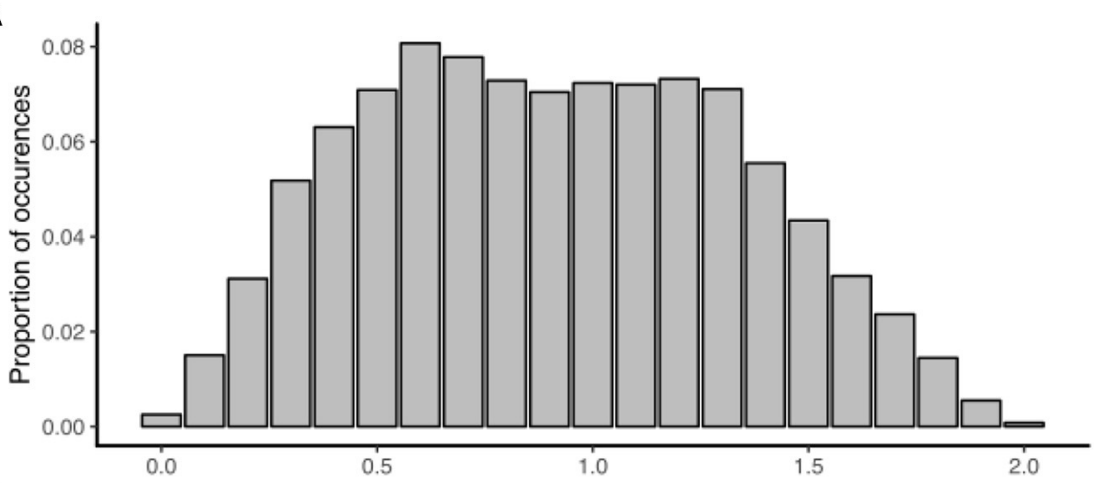

B

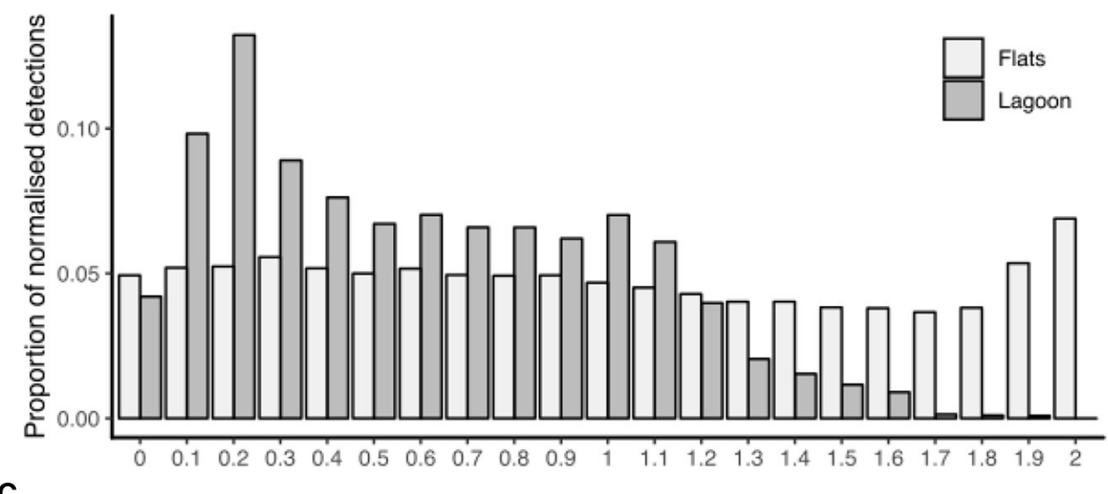

C

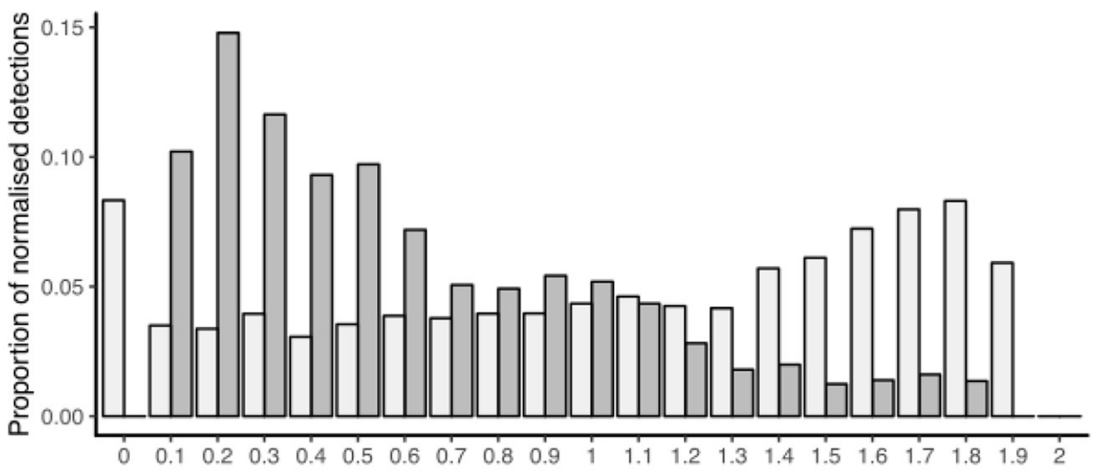

D

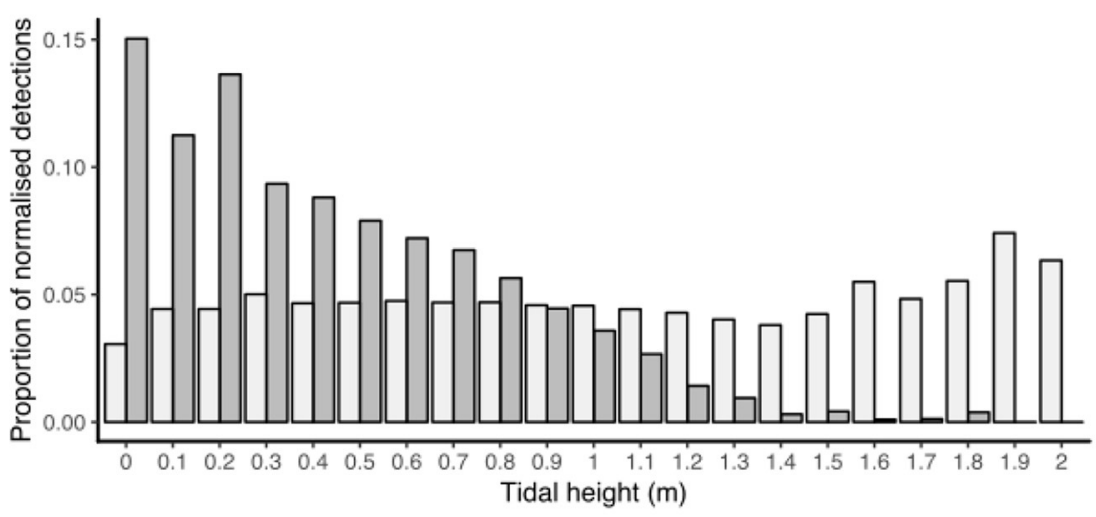

FIGURE 4 | Histogram of tidal height bin occurrences for June 2015-May 2016 in St. Joseph Atoll (A). The proportions of acoustic detections (normalized with the proportion of occurrences each tidal height bin) in each tidal height bin for each habitat type (reef flats or lagoon) recorded by P. ater (B), U. asperrimus (C), and U. granulatus (D). 
TABLE 5 | Outputs of the Generalized Linear Mixed Models testing whether diel stage, water temperature on the flats, tidal height, or precipitation influenced the probability of $P$. ater, $U$. asperrimus, and $U$. granulatus being detected in the reef flats or lagoon habitats of St. Joseph Atoll.

\begin{tabular}{|c|c|c|c|c|c|c|c|c|c|}
\hline \multicolumn{5}{|c|}{ SE-monsoon season } & \multicolumn{5}{|c|}{ NW-monsoon season } \\
\hline \multicolumn{10}{|c|}{ P. ater } \\
\hline Covariate & Co-efficient estimate & Std. error & z-value & p-value & Covariate & Co-efficient estimate & Std. error & z-value & p-value \\
\hline (Intercept) & -4.62 & 2.07 & 2.37 & 0.03 & (Intercept) & 7.29 & 1.33 & 5.69 & $<0.01$ \\
\hline Diel (dawn) & -0.58 & 0.13 & 4.45 & $<0.01$ & Diel (dawn) & -0.38 & 0.16 & 2.63 & $<0.01$ \\
\hline Diel (day) & -1.73 & 0.14 & 12.32 & $<0.01$ & Diel (day) & -1.31 & 0.12 & 10.95 & $<0.01$ \\
\hline Diel (dusk) & -0.26 & 0.16 & 1.70 & 0.12 & Diel (dusk) & -0.59 & 0.14 & 3.96 & $<0.01$ \\
\hline Temperature & 0.38 & 0.03 & 11.96 & $<0.01$ & Temperature & -0.14 & 0.03 & 5.73 & $<0.01$ \\
\hline Tidal height & 2.29 & 0.11 & 20.07 & $<0.01$ & Tidal height & 1.82 & 0.12 & 14.42 & $<0.01$ \\
\hline Rainfall & -0.03 & 0.15 & 0.22 & 0.82 & Rainfall & 0.01 & 0.04 & 0.38 & 0.76 \\
\hline \multicolumn{10}{|c|}{ U. asperrimus } \\
\hline Covariate & Co-efficient estimate & Std. error & z-value & p-value & Covariate & Co-efficient estimate & Std. error & z-value & p-value \\
\hline (Intercept) & 1.08 & 1.73 & 1.70 & 0.56 & (Intercept) & 6.69 & 1.02 & 7.49 & $<0.01$ \\
\hline Diel (dawn) & -0.01 & 0.16 & 1.28 & 0.41 & Diel (dawn) & 0.06 & 0.19 & 0.34 & 0.77 \\
\hline Diel (day) & -0.94 & 0.15 & 5.66 & $<0.01$ & Diel (day) & -0.53 & 0.12 & 3.92 & $<0.01$ \\
\hline Diel (dusk) & -0.17 & 0.22 & 0.11 & 0.47 & Diel (dusk) & 0.03 & 0.19 & 0.41 & 0.88 \\
\hline Temperature & 0.10 & 0.04 & 0.91 & 0.02 & Temperature & -0.19 & 0.03 & 8.59 & $<0.01$ \\
\hline Tidal height & 1.96 & 0.16 & 11.38 & $<0.01$ & Tidal height & 1.97 & 0.14 & 13.66 & $<0.01$ \\
\hline Rainfall & -0.03 & 0.12 & 0.07 & 0.81 & Rainfall & -0.01 & 0.05 & 0.39 & 0.77 \\
\hline \multicolumn{10}{|c|}{ U. granulatus } \\
\hline Covariate & Co-efficient estimate & Std. error & z-value & p-value & Covariate & Co-efficient estimate & Std. error & z-value & p-value \\
\hline (Intercept) & 3.11 & 1.80 & 1.73 & 0.08 & & & & & \\
\hline Diel (dawn) & -0.35 & 0.26 & 1.34 & 0.18 & & & & & \\
\hline Diel (day) & -0.65 & 0.20 & 3.32 & $<0.01$ & & & & & \\
\hline Diel (dusk) & 1.01 & 0.35 & 2.91 & $<0.01$ & & & & & \\
\hline Temperature & -0.01 & 0.04 & 0.23 & 0.82 & & & & & \\
\hline Tidal height & 2.31 & 0.22 & 10.58 & $<0.01$ & & & & & \\
\hline Rainfall & -0.01 & 0.37 & 0.03 & 0.97 & & & & & \\
\hline
\end{tabular}

thus they were found to occur in the lagoon more frequently during low tides. This is notwithstanding that the increased use of the lagoon at low tides may also relate to the avoidance of temperature extremes. The shallow waters at low tides on the flats become very warm (over $40^{\circ} \mathrm{C}$ ), which may be approaching the upper thermal maximum for these stingrays (Dabruzzi et al., 2013), driving them to seek out the cooler waters of the lagoon at low tides. Finally, stingrays in St. Joseph Atoll are known to feed on the flats (Elston et al., 2020) and the preferential use of this habitat may also be linked to foraging opportunities.

In this study, most individuals had diel peaks in detections and the diel stage significantly influenced habitat use. Previously identified elasmobranch diel movement patterns have been attributed to foraging or predator avoidance (Cartamil et al., 2003; Carlisle and Starr, 2010; Hammerschlag et al., 2017). If these were indeed the drivers behind diel movement patterns, one would expect a consistent pattern (Holland et al., 1993; Cartamil et al., 2003). However, in this study, there was high individual variability in the periodicity of diel peaks. This results reiterates that this atoll is a dynamic environment, where individuals likely have to balance a variety of environmental factors when using different habitat types.

The caveats of acoustic telemetry need to be addressed, specifically the potential effect that environmental factors may play on the detection efficiency of receivers and its subsequent role in the observed daily presence patterns. In the present study, the probability of daily detection was significantly negatively correlated with wind speeds and this trend could be influenced by receiver detection efficiency. Wind speed is known to reduce detection efficiency of receivers, both in this and other receiver arrays (Heupel et al., 2006; Elston et al., 2019). The SE-monsoon season is characterized by persistent strong winds and detections in this season were restricted when compared to the detections in the NW-monsoon season. However, the increase in detections recorded in the NW-monsoon season largely occurred in the deeper lagoon habitat, where wind is unlikely to have as large an effect on detection efficiency as on the shallow flats. This discrepancy suggests that these seasonal patterns in detections may not only be due to the changes in receiver detection efficiency but are likely driven by actual changes in movement 


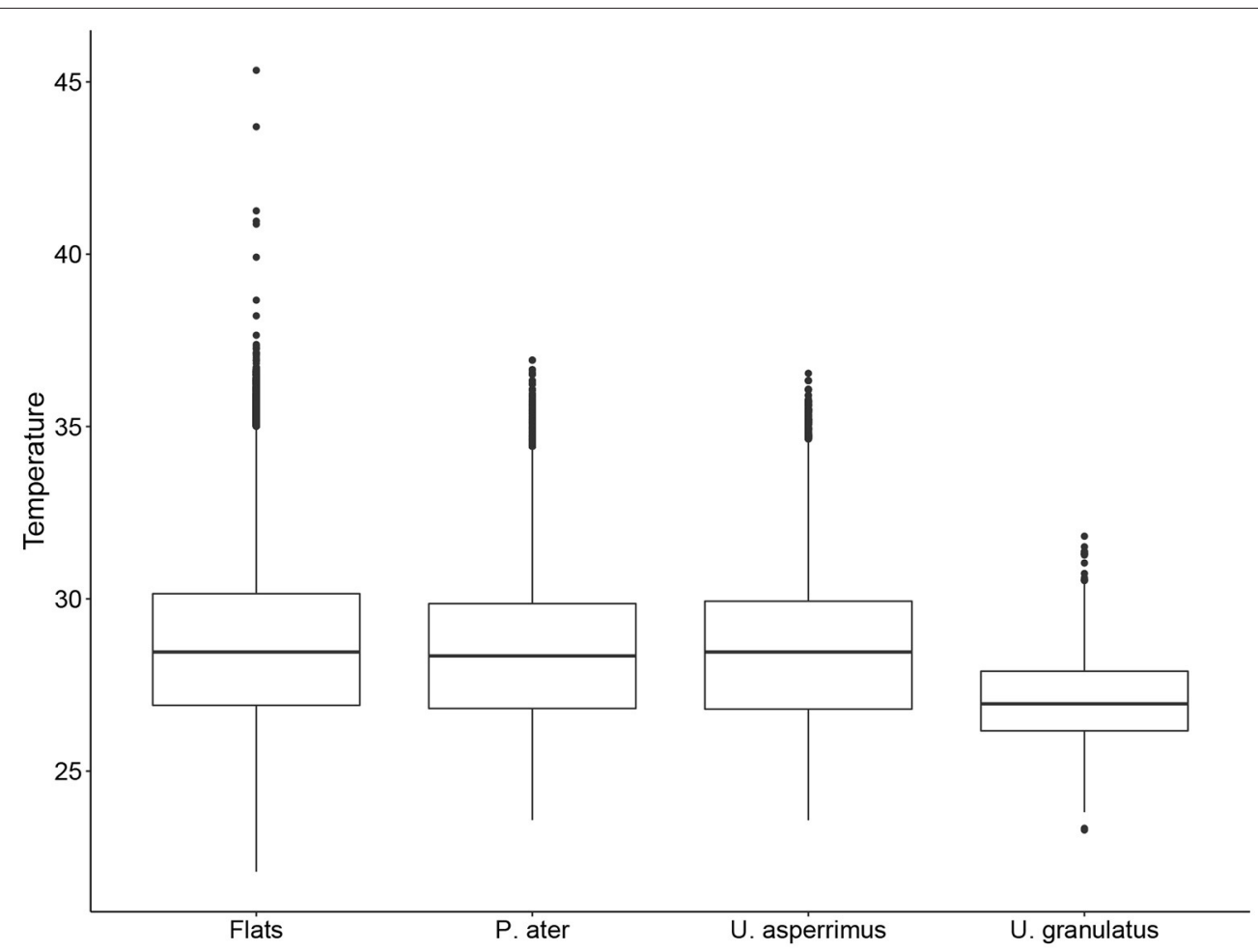

FIGURE 5 | Boxplot of mean hourly water temperatures $\left({ }^{\circ} \mathrm{C}\right)$ on the flats of St. Joseph Atoll, and the water temperatures on the flats when $P$. ater, $U$. asperrimus, and $U$. granulatus were present on the flats.

patterns. A further caveat is that the different transmitters types used in the study will have different rates of detectability due to factors such as power output and ping rate. The larger transmitters were implanted into the larger individuals, and indeed, larger individuals were found to have significantly higher edge and node densities in the networks constructed. This trend may, at least in part, be influenced by the different transmitters used.

Elasmobranchs have been hypothesized to be highly susceptible to the effects of climate change, and this is specifically true for U. asperrimus (Chin et al., 2010). The significant influence of temperature on habitat use found in the present study supports this notion, and may suggest that these species will be significantly effected by climate change induced temperatures. Specifically, with increasing temperatures, individuals may need to increase their utilization of the lagoon habitat to keep metabolic rates at optimal levels. This is important as increased metabolic rates have been linked to losing body mass in elasmobranchs, potentially reaching lethal levels under future climate change scenarios (Lear et al., 2020). Thus, species using shallow water environments, such as atolls, with may be at greater risk to the effects of warming water temperatures and may need to significantly alter habitat use patterns to survive. Future work could focus on exactly how temperature may influence stingray physiology, for example determining metabolic rates under various temperature regimes, to fill in the gaps of understanding how changing temperatures may influence the survival potential of these animals. The interplay between how tides and temperature effected habitat use in stingrays was dynamic, but relatively consistent between stingray species, highlighting how important the physical environment is on determining habitat use in stingrays.

\section{DATA AVAILABILITY STATEMENT}

The raw data supporting the conclusions of this article will be made available by the authors, without undue reservation.

\section{ETHICS STATEMENT}

The animal study was reviewed and approved by South African Institute for Aquatic Biodiversity Ethics Committee.

\section{AUTHOR CONTRIBUTIONS}

$\mathrm{CE}, \mathrm{PC}$, and $\mathrm{RB}$ conceived and developed the project. CE performed data analysis and wrote the first draft of the manuscript. PC, RB, and JL edited the manuscript. PC and RB were supervisors of the project. All authors contributed toward data collection. 


\section{FUNDING}

This research was supported by a grant obtained from the Save Our Seas Foundation Keystone (Grant number 288). CE received a scholarship from the South African National Research Foundation.

\section{ACKNOWLEDGMENTS}

The authors gratefully acknowledge the Save Our Seas Foundation which provided the funds to carry out this study, as well as the National Research Foundation and South African Institute of Aquatic Biodiversity that provided additional funds. We also thank the staff and volunteers of the Save Our

\section{REFERENCES}

Anderson, M. J. (2001). A new method for non-parametric multivariate analysis of variance. Austral Ecol. 26, 32-46. doi: 10.1111/j.1442-9993.2001.01070.pp.x

Bates, D. M. (2010). Ime4: Mixed-Effects Modeling With R. Vienna: Springer.

Bauer, S., and Klaassen, M. (2013). Mechanistic models of animal migration behaviour - their diversity, structure and use. J. Anim. Ecol. 82, 498-508. doi: 10.1111/1365-2656.12054

Brinton, C., and Curran, M. (2017). Tidal and diel movement patterns of the Atlantic stingray (Dasyatis sabina) along a stream-order gradient. Mar. Freshw. Res. 68, 1716-1725. doi: 10.1071/MF16073

Brown, J. H., Gillooly, J. F., Allen, A. P., Savage, V. M., and West, G. B. (2004). Toward a metabolic theory of ecology. Ecology 85, 1771-1789. doi: 10.1890/03-9000

Carlisle, A. B., and Starr, R. M. (2010). Tidal movements of female leopard sharks (Triakis semifasciata) in Elkhorn Slough, California. Environ. Biol. Fish. 89, 31-45. doi: 10.1007/s10641-010-9667-0

Cartamil, D. P., Vaudo, J. J., Lowe, C. G., Wetherbee, B. M., and Holland, K. N. (2003). Diel movement patterns of the Hawaiian stingray, Dasyatis lata: implications for ecological interactions between sympatric elasmobranch species. Mar. Biol. 142, 841-847. doi: 10.1007/s00227-003-1014-y

Cerutti-Pereyra, F., Thums, M., Austin, C. M., Bradshaw, C. J. A., Stevens, J. D., Babcock, R. C., et al. (2014). Restricted movements of juvenile rays in the lagoon of Ningaloo Reef, Western Australia - evidence for the existence of a nursery. Environ. Biol. Fish. 97, 371-383. doi: 10.1007/s10641-0130158-y

Chapman, D. D., Feldheim, K. A., Papastamatiou, Y. P., and Hueter, R. E. (2015). There and back again: a review of residency and return migrations in sharks, with implications for population structure and management. Annu. Rev. Mar. Sci. 7, 547-570. doi: 10.1146/annurev-marine-010814-015730

Chin, A., Kyne, P. M., Walker, T. I., and McAuley, R. B. (2010). An integrated risk assessment for climate change: analysing the vulnerability of sharks and rays on Australia's Great Barrier Reef. Glob. Change Biol. 16, 1936-1953. doi: 10.1111/j.1365-2486.2009.02128.x

Csardi, G., and Nepusz, T. (2006). The igraph software package for complex network research. InterJournal Complex Syst. 1695, 1-9.

Dabruzzi, T. F., and Bennett, W. A. (2014). Hypoxia effects on gill surface area and blood oxygen-carrying capacity of the Atlantic stingray, Dasyatis sabina. Fish Physiol. Biochem. 40, 1011-1020. doi: 10.1007/s10695-0139901-8

Dabruzzi, T. F., Bennett, W. A., Rummer, J. L., and Fangue, N. A. (2013). Juvenile Ribbontail Stingray, Taeniura lymma (Forsskal, 1775) (Chondrichthyes, Dasyatidae), demonstrate a unique suite of physiological adaptations to survive hyperthermic nursery conditions. Hydrobiologia 701, 37-49. doi: 10.1007/s10750-012-1249-Z

Dale, J. J., Drazen, J. C., and Holland, K. N. (2013). Stingray life history trade-offs associated with nursery habitat use inferred from a bioenergetics model. Mar. Biol. 160, 3181-3192. doi: 10.1007/s00227-013-2305-6
Seas Foundation-D'Arros Research Center (SOSF-DRC) for their assistance in the field and use of facilities and equipment, in particular, R. and C. Daly, K. Bullock, C. Boyes, D. Howell, R. Bennett, and E. Moxham. We are grateful to Danah Divers and SOSF-DRC for the installation and maintenance of the receiver array as well as the downloading and maintenance of the database.

\section{SUPPLEMENTARY MATERIAL}

The Supplementary Material for this article can be found online at: https://www.frontiersin.org/articles/10.3389/fmars. 2021.754404/full\#supplementary-material

Davy, L. E., Simpfendorfer, C. A., and Heupel, M. R. (2015). Movement patterns and habitat use of juvenile mangrove whiprays (Himantura granulata). Mar. Freshw. Res. 66:481. doi: 10.1071/MF14028

DiGirolamo, A. L., Gruber, S. H., Pomory, C., and Bennett, W. A. (2012). Diel temperature patterns of juvenile lemon sharks Negaprion brevirostris, in a shallow-water nursery. J. Fish Biol. 80, 1436-1448. doi: 10.1111/j.1095-8649.2012.03263.x

Dulvy, N. K., Pacoureau, N., Rigby, C. L., Pollom, R. A., Jabado, R. W., Ebert, D. A., et al. (2021). Overfishing drives over one-third of all sharks and rays toward a global extinction crisis. Curr. Biol. 31, 4773.e8-4787.e8. doi: 10.1016/j.cub.2021.08.062

Egbert, G. D., and Erofeeva, S. Y. (2002). Efficient inverse modeling of barotropic ocean tides. J. Atmos. Ocean. Technol. 19, 183-204. doi: 10.1175/1520-0426(2002)019<0183:EIMOBO>2.0.CO;2

Elston, C., Brandis, R. G. V., and Cowley, P. D. (2017). Dietary composition and prey selectivity of juvenile porcupine rays Urogymnus asperrimus. J. Fish Biol. 91, 429-442. doi: 10.1111/jfb.13334

Elston, C., Cowley, P. D., Brandis, R. G. V., and Lea, J. (2021). Residency and habitat use patterns by sympatric stingrays at a remote atoll in the Western Indian Ocean. Mar. Ecol. Prog. Ser. 662, 97-114. doi: 10.3354/meps13632

Elston, C., Cowley, P. D., and von Brandis, R. G. (2019). Movement patterns of juvenile porcupine rays Urogymnus asperrimus at a remote atoll: a potential nursery ground within a proposed marine protected area. Environ. Biol. Fish. 102, 1485-1498. doi: 10.1007/s10641-019-00927-x

Elston, C., Cowley, P. D., von Brandis, R. G., and Fisk, A. (2020). Dietary niche differentiation in a mesopredatory dasyatid assemblage. Mar. Biol. 167:89. doi: 10.1007/s00227-020-03695-w

Fangue, N. A., and Bennett, W. A. (2003). Thermal tolerance responses of laboratory acclimated and seasonally acclimatized Atlantic stingray, Dasyatis sabina. Copeia 2003, 315-325. doi: 10.1643/0045-8511(2003)003[0315:TTROLA]2.0.CO;2

Filmalter, J. D., Dagorn, L., and Cowley, P. D. (2013). Spatial behaviour and site fidelity of the sicklefin lemon shark Negaprion acutidens in a remote Indian Ocean atoll. Mar. Biol. 160, 2425-2436. doi: 10.1007/s00227-013-2237-1

Flowers, K. I., Ajemian, M. J., Bassos-Hull, K., Feldheim, K. A., Hueter, R. E., Papastamatiou, Y. P., et al. (2016). A review of batoid philopatry, with implications for future research and population management. Mar. Ecol. Prog. Ser. 562, 251-261. doi: 10.3354/meps11963

Hammerschlag, N., Calich, H., Wester, J., Cain, S., Jennings, L., and Enchelmaier, A. (2017). Nocturnal and crepuscular behavior in elasmobranchs: a review of movement, habitat use, foraging, and reproduction in the dark. Bull. Mar. Sci. 93, 355-374. doi: 10.5343/bms.2016.1046

Hammerschlag, N., Gallagher, A., and Lazarre, D. (2011). A review of shark satellite tagging studies. J. Exp. Mar. Biol. Ecol. 398, 1-8. doi: 10.1016/j.jembe.2010.12.012

Heupel, M. R., Semmens, J. M., and Hobday, A. J. (2006). Automated acoustic tracking of aquatic animals: scales, design and deployment of listening station arrays. Mar. Freshw. Res. 57:113. doi: 10.1071/MF05091 
Hight, B. V., and Lowe, C. G. (2007). Elevated body temperatures of adult female leopard sharks, Triakis semifasciata, while aggregating in shallow nearshore embayments: evidence for behavioral thermoregulation? J. Exp. Mar. Biol. Ecol. 352, 114-128. doi: 10.1016/j.jembe.2007.07.021

Holland, K. N., Wetherbee, B. M., Peterson, J. D., and Lowe, C. G. (1993). Movements and distribution of hammerhead shark pups on their natal grounds. Copeia 2:495. doi: 10.2307/1447150

Hopkins, T. E., and Cech, J. J. (2003). The influence of environmental variables on the distribution and abundance of three elasmobranchs in Tomales Bay, California. Environ. Biol. Fish. 66, 279-291. doi: 10.1023/A:1023907121605

Jacoby, D. M. P., Brooks, E. J., Croft, D. P., and Sims, D. W. (2012). Developing a deeper understanding of animal movements and spatial dynamics through novel application of network analyses. Methods Ecol. Evol. 3, 574-583. doi: 10.1111/j.2041-210X.2012.00187.x

Jirik, K. E., and Lowe, C. G. (2012). An elasmobranch maternity ward: female round stingrays Urobatis halleri use warm, restored estuarine habitat during gestation. J. Fish Biol. 80, 1227-1245. doi: 10.1111/j.1095-8649.2011.03208.x

Lea, J. S. E. (2017). Migratory behaviour and spatial dynamics of large sharks and their conservation implications (Ph.D. thesis). University of Plymouth, Plymouth, United Kingdom.

Lea, J. S. E., Humphries, N. E., Bortoluzzi, J., Daly, R., von Brandis, R. G., Patel, E., et al. (2020). At the turn of the tide: Space use and habitat partitioning in two sympatric shark species is driven by tidal phase. Front. Mar. Sci. 7:624. doi: 10.3389/fmars.2020.00624

Lea, J. S. E., Humphries, N. E., von Brandis, R. G., Clarke, C. R., and Sims, D. W. (2016). Acoustic telemetry and network analysis reveal the space use of multiple reef predators and enhance marine protected area design. Proc. R. Soc. B Biol. Sci. 283:20160717. doi: 10.1098/rspb.2016.0717

Lear, K. O., Morgan, D. L., Whitty, J. M., Whitney, N. M., Byrnes, E. E., Beatty, S. J., et al. (2020). Divergent field metabolic rates highlight the challenges of increasing temperatures and energy limitation in aquatic ectotherms. Oecologia 193, 311-323. doi: 10.1007/s00442-020-04669-x

Matern, S. A., Cech, J. J., and Hopkins, T. E. (2000). Diel movements of bat rays, Myliobatis californica, in Tomales Bay, California: evidence for behavioral thermoregulation? Environ. Biol. Fish. 58, 173-182. doi: 10.1023/A:1007625212099

Morris, D. W. (2003). Toward an ecological synthesis: a case for habitat selection. Oecologia 136, 1-13. doi: 10.1007/s00442-003-1241-4

Næsje, T. F., Cowley, P. D., Diserud, O. H., Childs, A. R., Kerwath, S. E., and Thorstad, E. B. (2012). Riding the tide: estuarine movements of a sciaenid fish, Argyrosomus japonicus. Mar. Ecol. Prog. Ser. 460, 221-232. doi: $10.3354 /$ meps,09780

R Core Team (2020). R: A Language and Environment for Statistical Computing. Vienna: R Foundation for Statistical Computing.

Rey, A. R., Bost, C.-A., Schiavini, A., and Pütz, K. (2010). Foraging movements of Magellanic penguins Spheniscus magellanicus in the Beagle Channel, Argentina, related to tide and tidal currents. J. Ornithol. 151, 933-943. doi: 10.1007/s10336-010-0531-y

Rogers, D. I., Battley, P. F., Piersma, T., Van Gils, J. A., and Rogers, K. G. (2006). High-tide habitat choice: insights from modelling roost selection by shorebirds around a tropical bay. Anim. Behav. 72, 563-575. doi: 10.1016/j.anbehav.2005.10.029

Sakabe, R., and Lyle, J. M. (2010). The influence of tidal cycles and freshwater inflow on the distribution and movement of an estuarine resident fish Acanthopagrus butcheri. J. Fish Biol. 77, 643-660. doi: 10.1111/j.1095-8649.2010.02703.x

Schlaff, A. M., Heupel, M. R., and Simpfendorfer, C. A. (2014). Influence of environmental factors on shark and ray movement, behaviour and habitat use: a review. Rev. Fish Biol. Fish. 24, 1089-1103. doi: 10.1007/s11160-014-9364-8

Sims, D. W. (2003). Tractable models for testing theories about natural strategies: foraging behaviour and habitat selection of free-ranging sharks. J. Fish Biol. 63, 53-73. doi: 10.1111/j.1095-8649.2003.00207.x

Sims, D. W. (2010). "Tracking and analysis techniques for understanding freeranging shark movements and behavior," in Sharks and Their Relatives II: Biodiversity, Adaptive Physiology, and Conservation, eds J. C. Carrier, J. A. Musick, and M. R. Heithaus (Boca Raton, FL: CRC Press), 367-408. doi: 10.1201/9781420080483-c8

Sims, D. W., Wearmouth, V. J., Southall, E. J., Hill, J. M., Moore, P., Rawlinson, K., et al. (2006). Hunt warm, rest cool: bioenergetic strategy underlying diel vertical migration of a benthic shark. J. Anim. Ecol. 75, 176-190. doi: $10.1111 /$ j.1365-2656.2005.01033.x

Smith, D. T., and Curran, M. C. (2017). Movement patterns of Sphyrna tiburo (bonnethead shark) in a shallow tidal creek system. Southeastern Natural. 16, 297-316. doi: 10.1656/058.016.0213

Speed, C., Field, I., Meekan, M., and Bradshaw, C. (2010). Complexities of coastal shark movements and their implications for management. Mar. Ecol. Prog. Ser. 408, 275-293. doi: 10.3354/meps08581

Speed, C., Meekan, M., Field, I., McMahon, C., and Bradshaw, C. (2012). Heatseeking sharks: support for behavioural thermoregulation in reef sharks. Mar. Ecol. Prog. Ser. 463, 231-245. doi: 10.3354/meps09864

Stoddart, D. R., Coe, M. J., and Fosberg, F. R. (1979). D'Arros and St. Joseph, Amirante Islands. Atoll Res. Bull. 223, 1-48. doi: 10.5479/si.00775630.223.1

Vaudo, J. J., and Heithaus, M. R. (2013). Microhabitat selection by marine mesoconsumers in a thermally heterogeneous habitat: behavioral thermoregulation or avoiding predation risk? PLoS ONE 8:e61907. doi: 10.1371/journal.pone.0061907

Vaudo, J. J., and Lowe, C. G. (2006). Movement patterns of the round stingray Urobatis halleri (Cooper) near a thermal outfall. J. Fish Biol. 68, 1756-1766. doi: $10.1111 /$ j.0022-1112.2006.01054.x

Conflict of Interest: The authors declare that the research was conducted in the absence of any commercial or financial relationships that could be construed as a potential conflict of interest.

Publisher's Note: All claims expressed in this article are solely those of the authors and do not necessarily represent those of their affiliated organizations, or those of the publisher, the editors and the reviewers. Any product that may be evaluated in this article, or claim that may be made by its manufacturer, is not guaranteed or endorsed by the publisher.

Copyright (c) 2022 Elston, Cowley, von Brandis and Lea. This is an open-access article distributed under the terms of the Creative Commons Attribution License (CC $B Y)$. The use, distribution or reproduction in other forums is permitted, provided the original author(s) and the copyright owner(s) are credited and that the original publication in this journal is cited, in accordance with accepted academic practice. No use, distribution or reproduction is permitted which does not comply with these terms. 